\title{
CMPA not an insurer, NB court told
}

$\mathrm{D}$ octors in Canada may be surprised to learn that the Canadian Medical Protective Association (CMPA) does not provide insurance to physicians and has no obligation to pay damages levied against them. Those contentions are currently being challenged in the New Brunswick (NB) Court of Queen's Bench.

The case involves a woman who the Court of Queen's Bench found had been sexually and emotionally abused by her former psychiatrist. Dr. K.A. Akuffo-Akoto was subsequently struck from the registry by the College of Physicians and Surgeons of New Brunswick. In 2004, the patient and her husband sued Akuffo-Akoto, who had fled the country around 1997, and were awarded more than $\$ 550000$ in damages. Collecting on the judgment, however, has proven difficult.

Unable to collect from the missing psychiatrist, the patient's lawyer claimed damages from what he believed to be the psychiatrist's insurer: the CMPA. However, the association refused to pay, stating that they are not an insurance company. "They say they are a paternal organization and doctors join as mem-

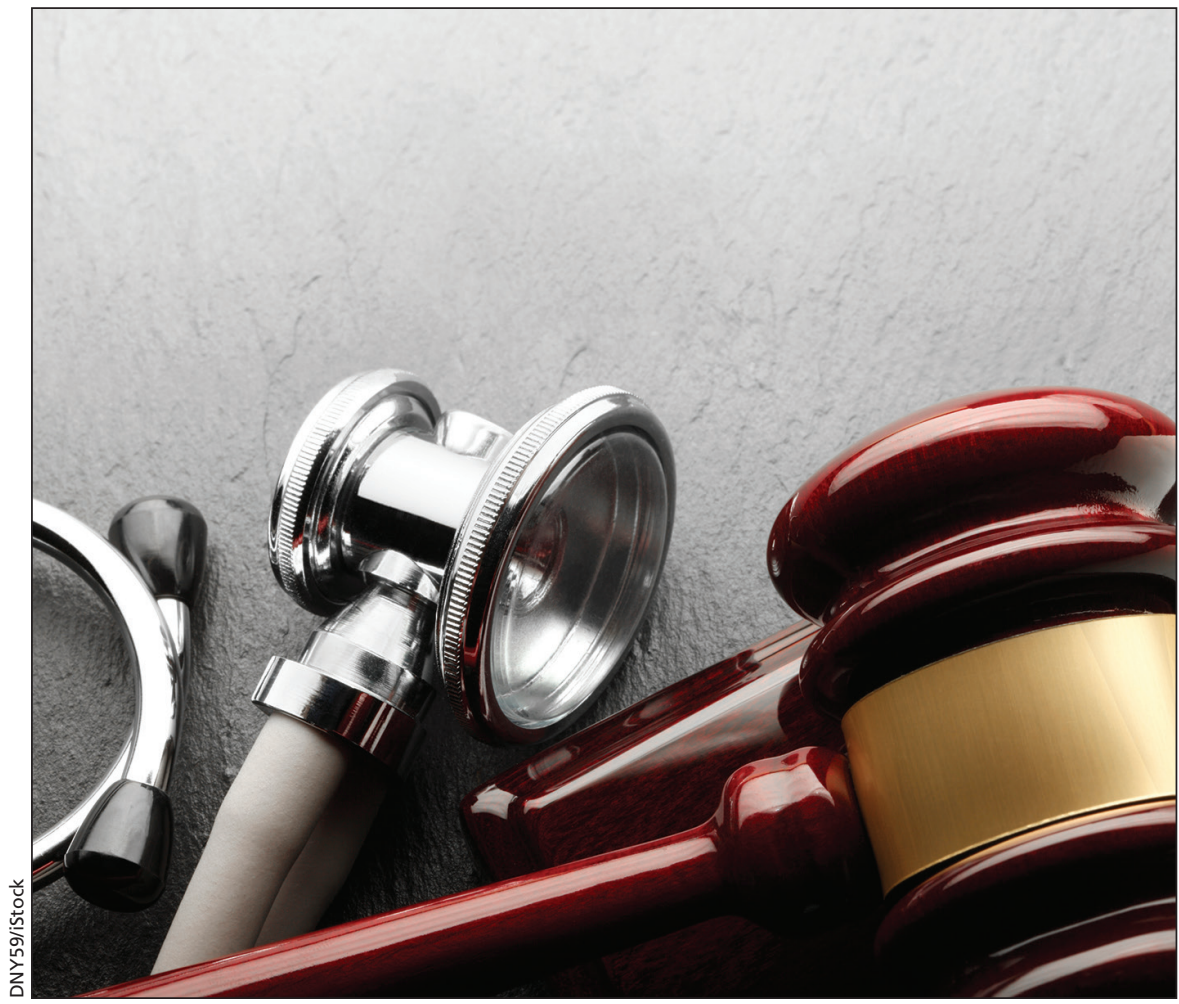

A New Brunswick court will decide if the Canadian Medical Protective Association is an insurer and therefore obligated to pay damages levied against them.

ceived as an insurance company by the provincial medical association and in

\section{"They say they are a paternal organization, and doctors join as members."}

bers," Pete Mockler, a Fredericton lawyer representing the patient and her husband, told CMAJ.

The CMPA declined to speak about the case, which is now before the courts. However, in its statement of defence, the association did deny that it is an insurer as legally defined and described itself as "a not-for-profit medical mutual defence organization." As a member-based organization, the CMPA said its bylaws authorize it to "consider an application for assistance and to decide whether it will grant assistance and, if so, on what terms."

Mockler and his clients are challenging this official description and contend that the CMPA is an insurance company under the New Brunswick Insurance Act, as well as being per- the minds of most doctors. "In New Brunswick, there is a legal obligation to be insured in order to be licensed," Mockler said. The Court of the Queen's Bench of New Brunswick is being asked to determine if it is the CMPA that fulfills that role.

The situation is compounded by the nature of the psychiatrist's actions. The CMPA has taken the position that it will not generally pay damages to victims of sexual assault even when a courtordered judgment is issued against a physician. This summer, CMPA lawyer Ken McCullogh told the Court of Queen's Bench that the association pays compensation only for negligent medical care, not for the criminal acts of doctors.

Mockler argues that the abuse and mistreatment suffered by his client, who was seriously injured after a related suicide attempt, constitutes negligent medical care. "This woman was treated by a psychiatrist for three years during which he [over]prescribed medicine, undermined her relationship with her husband and advised her to go to a bar and see who she could pick up," he said.

Mockler contends that this is also a public policy issue, given that the province partially reimburses the roughly $\$ 8$ million in membership fees paid annually by New Brunswick doctors to the CMPA. "The people of New Brunswick have a right to assume protection will be there," he said. "As a matter of public policy, you can't run a protection organization that holds out to the public that they're covered then [not follow through]."

Briefs in the case had to be filed by the end of September, and the judge has indicated a decision will likely be handed down by the end of the year. donalee Moulton, Halifax, NS 